\title{
'To Be Is To Respond': Realising a Dialogic Ontology For Deweyan Pragmatism
}

\author{
Pre-publication version
}

\section{RUPERT HIGHAM}

Dewey's pragmatism rejected 'truth' as indicative of an underlying reality, instead ascribing it to valuable connections between aims and ends. Surprisingly, his argument mirrors Bishop Berkeley's Idealism, summarised as 'esse est percepi' (to be is to be perceived), whose thinking is shown to be highly pragmatist - but who retained a foundationalist ontology by naming God as the guarantor of all things. I argue that while this position is unsustainable, pragmatism could nonetheless be strengthened through an ontological foundation.

Koopman's charges of foundationalist 'givenism' in Dewey's work, and in his promotion of the scientific method, are not proven. However, Koopman's 'genealogical pragmatism' may develop Deweyan educational theory by addressing dilemmas around curricular study. Koopman's arguments also point towards a missing ontological piece in Dewey's theory of knowledge. In the final section of the article I offer a dialogic ontology as compatible with pragmatism. This dialogical ontology provides both an ethical foundation through interrelatedness, and a generative theory of meaning and experience, as emergent from the encounter with difference. In this framework, to be is to respondor be responded to. I offer the metaphor of 'realisation' to capture the human experience implied by this ontological stance.

\section{INTRODUCTION}

John Dewey's Democracy and Education has profoundly shaped my thinking through its humane vision of the role of education in society, and the scope and power of its analysis. To mark the centenary of its publication I want to explore how Dewey's radical alternative to traditional views of the processes of coming to know, and of education more broadly, might be enriched by a return to ontological questions that he studiously avoided. Just as pragmatism offered a different sort of epistemology, one without reference to either an objective or subjective reality, I would like to offer a different sort of ontology, one without metaphysics, which complements and strengthens Deweyan pragmatism-particularly his concepts of growth and communication.

Seeking to escape the stranglehold of traditional representationalist ontology, in which an underlying material reality is the source and guarantor of the truth of our perceptions and beliefs, Dewey opts in this book for ontological agnosticism: he puts aside the vexed issue of the nature of reality to address the more urgent business of 
how we come to understand and act in the world intelligently and democratically. This remodelling of experience, interaction and meaning-making underpins more recent influential educational theories of knowledge and democratic participation, notably that of Biesta (2006). Koopman (2009) also seeks to build on Dewey in presenting a model of transitionalist pragmatism. He argues that Dewey's writings sometimes lapse into an inadvertent foundationalism that is best remedied by hybridising 'classicopragmatism', which focuses on experience as the spur to meaningful understanding and action, with the linguistic 'neopragmatism' of Rorty, Sellars and Brandom, which focuses on language instead (Koopman, 2009). This allegation of a flaw in Dewey's theory of inquiry has been strongly contested (Frega, 2009; Hildebrand and Pappas, 2010; Margolis, 2012). Rather than a flaw, then, I have been spurred by Koopman's critique to argue there may be something missing in Dewey's analysis that shows through at times in his writing-which an ontological underpinning can provide.

In seeking that missing element, I will examine the parallels between Dewey's pragmatism and that of Bishop George Berkeley, an English philosopher writing two centuries previously. Despite these parallels, Berkeley maintains a clear ontological stance - that to be is to be perceived - and that the existence of all is guaranteed in the omnipercipient mind of God. While rejecting this argument, I will suggest that Berkeley was right (or perhaps, prescient) to insist on an ontological foundation for his understanding of thought and experience.

I will then make the case for dialogic theory, as outlined by Wegerif (2008), as a more credible and powerful ontological foundation for pragmatism. Its central metaphor of 'dialogic space' implies that meanings emerge from the gaps that open up between different perspectives, and thus that difference itself gives rise to meaningful thought and action and offers a source of growth. Further, this theoretical perspective neatly dovetails with that of Biesta, whose neo-existentialist notion of 'coming into presence' (Biesta, 2001, p. 398) operationalises a dialogic ontology both as an ethical imperative and as a framework for understanding democratic agency. The key to both, I will argue, is the concept of response to difference, sometimes characterised as 'the Other'. Together, I will argue, they can serve as the missing piece in Dewey's picture.

Finally, by the way of integrating dialogic ontology with pragmatist epistemology, I will offer two metaphors: first, by changing Berkeley's 'to be is to be perceived' to 'to be is to respond, and be responded to'; second, by suggesting that 'realisation', or more properly, 'realising', captures both the ontological basis and the human experience implied by this combined theoretical perspective. This theoretical hybrid, shared implicitly or explicitly through pedagogy, can deepen people's motivation to learn with, about and from each other, and from the world.

Bringing these diverse lines of argument together in one article requires regrettable brevity in places; in particular, I rely on giving brief synopses of Friedman's, Koopman's and Wegerif's arguments rather than the detailed exploration they deserve. I hope that responses to my broad claim here will help me to elaborate and strengthen my case in the future.

\section{Berkeley's Search for a Pragmatist Theory of Knowledge and Action}

Over 300 years ago, Bishop George Berkeley's Treatise Concerning the Principles of Human Knowledge (1988 [1710]) provided a powerful critique of realist foundationalism that prefigures pragmatism in several important ways-so much so that Charles Peirce said of him, 'Berkeley on the whole has more right to be 
considered the introducer of pragmatism into philosophy than any other one man' (1903 letter to William James, in Friedman, 2003, p. 81). As Friedman points out, Berkeley's definition of concepts, his understanding of habit as the consistent attribution of cause and effect, and his rejection of objects' metaphysical status as unknowable and unhelpful, are all strongly pragmatic. While often labelled an empiricist, his enquiries were not underpinned by any experimentation-other than in critical thought. Above all, his desire to cut away unnecessary terminology and entities was pragmatic in spirit:

'[Berkeley] advises: "Think with the learned and speak with the vulgar"-we may make use of any phrases we wish "so long as they excite in us proper sentiments, or dispositions to act in such as manner as is necessary for our well-being"' (Friedman, 2003, p. 92).

The phraseology here-'proper sentiments', 'dispositions to act' - and the focus on the use of words in initiating actions and valuable outcomes rather than evoking abstract realms of existence, is eerily reminiscent of Dewey: Berkeley here is seeking to understand perceiving, thinking, feeling and action as interrelated activities that are, in Koopman's phrase, 'melioristic' (2009, p. 9), or aimed at improvement. Berkeley's riposte to common attempts to describe this process in terms of a connection between 'perception' and 'reality' is somewhat scornful:

'It is indeed an opinion strangely prevailing amongst men, that houses, mountains, rivers, and in a word all sensible objects, have an existence, natural or real, distinct from their being perceived by the understanding. But ... what are the fore-mentioned objects but the things we perceive by sense? And what do we perceive besides our own ideas or sensations? And is it not plainly repugnant that any one of these, or any combination of them, should exist unperceived?' (Berkeley, 1988 [1710], p. 54).

This elegant argument for the redundancy of an external material reality also proposes an empiricist theory of how we combine changing sensations and ideas to make objects meaningful and distinct in our minds. He had explored this more fully in his Essay Towards a New Theory of Vision, arguing that since we cannot perceive the distance of an object directly, we infer it through a 'habitual or customary connexion' (Berkeley, 1948 [1709], p. 17) of relevant ideas. Thus he argues for a collapse of the dualism between mind and world so central to Dewey's highly empirical pragmatism.

Yet despite these remarkable parallels, Berkeley's position was explicitly foundationalist. As with the contemporary philosophers of optics whose work he sought to challenge, Berkeley focused on vision as the basis for his conception of reality. To be is to be perceived - and thus the guarantor of the existence of all things not perceived at any given time by 'spirits' such as you and I, must be an omnipercipient God. This position has been much criticised-perhaps dismissively, by Samuel Johnson's kicking of a stone and saying, 'I refute it thus!' (Patey, 1986, p. 139); perhaps fatally, by arguing that Berkeley's God is as imperceptible and unfalsifiable as the material reality he seeks to undermine. Even Peirce, his strongest advocate, expressed his surprise and perplexity on this point: 
'... that he should be capable of falling into so glaring a contradiction with his principle ... the contradiction consists in his here making the existence of the thing consist, not in its being perceived, but in its being capable of being perceived. Now the difference between actuality and possibility is surely most important when it is existence that is in question' (Peirce in Friedman, 2003, p. 88).

Yet Peirce's hypothetical theory of existence-'countenancing the reality of "would-be's"" (Friedman, 2003, p. 89) is, I suggest, rather thin and circuitous. The concept of 'the capacity to be perceived' as the mark of the reality of things may help us to distinguish waking from dreaming, the proven from the unproven. Further, suggesting that something might be experienced in certain circumstances is useful in relation to Dewey's notion of thinking, which he describes as relating to 'the possibility of hypothetical conclusions, of tentative results' (1966 [1916], p. 149, italics in original). Yet the idea of granting reality to the possible does little justice to the crucially immanent nature of embodied experience, which acts as the confirmation or denial of our hypothetical thinking. Importantly, it also does little for us in providing a generative ontology, one that could account for how things become capable of being experienced. For Berkeley, the vision of God was the sustaining force behind our perceptions, but God was also the creative force through which the possibility of perception, and of perceivers, comes into being. While his theory cannot stand, I suggest his search for a generative, creative ontological force was important.

\section{Dewey's Ontological Agnosticism}

Berkeley's failure to provide a secure ontological foundation to his pragmatist thinking, and Peirce's unsatisfying attempt at an anti-foundational alternative, suggest why Dewey may have sought to avoid the attempt entirely. In Democracy and Education, rather than openly embracing or rejecting either God or an underlying material reality, Dewey takes an agnostic stance by choosing to focus instead on what we can usefully know through a pragmatist lens:

'Knowledge, then, is the ability to employ things with a purpose-we have had experience with them that enables us to predict how they will react. It is intimate, not abstract' (Dewey, 1966 [1916], p. 185).

In line with Berkeley's passion for eliminating redundancy, Dewey seeks to obviate the need for abstract ontological speculation by leaving no room for it in an account of our knowing through engagement with the world. Koopman, however, has argued that there are leaks in the seals of Dewey's anti-foundationalism that require fixing by hybridising what he calls 'classicopragmatism' with the linguistic 'neopragmatism' of scholars such as Rorty and Brandom. In this section, I will briefly explore this argument and the counterarguments, and subsequently suggest that while Koopman's case is not proven, it nonetheless helps to highlight what I argue is the missing element in Dewey's thinking. I must stress that these arguments are between scholars with a deep knowledge of Dewey and other pragmatists that I do not claim the personal authority to rule on; I overview them principally to illustrate how these tensions have provoked my own distinctive response-which is to suggest how Deweyan pragmatism might be strengthened with an anti-foundationalist ontological stance. 
Koopman (2009) recognises that Dewey's philosophy is essentially, and by explicit intention, anti-foundational. That said, he then points to a series of examples where he argues that Dewey's use of language, and that of other 'classicopragmatist' philosophers, nonetheless could be interpreted as implying that experience itself acts as a foundation for knowledge. For example, he quotes from Dewey's Experience and Nature where Dewey explains that primary experience 'furnishes the first data of the reflection which constructs the secondary objects' such that 'test and verification of the latter is secured only by return to the things of crude or macroscopic experience' (Koopman, 2009, pp. 79-80).

For Koopman, this is an inadvertent slip into suggesting that "primary experience' is of a different order that is presented to us wholesale as a given, rather than retail as mediated through our previous experiences, knowledge, understandings and aims - and that it thus assumes the prior existence of objects of perceptions or knowledge independent of the observer. He then defends Dewey from his own accusations on the grounds that he was unable to benefit from the warnings of subsequent philosophers who demonstrated the perniciousness of foundationalism in accounts of experience, particularly Sellars' (1956) 'myth of the given'. Such warnings, he suggests, would have prompted Dewey to have expressed himself more carefully.

Hildebrand and Pappas' (2010) response has two main strands. First, they argue that Koopman's picking out of examples from Dewey's work is partial and unrepresentative, that his claim that there are infrequent but consistent ambiguities in Dewey's expression around experience simply doesn't stand up in the face of the many clear statements of position Dewey gave, for example:

'... experience is already overlaid and saturated with the products of the reflection of past generations and by-gone ages. It is filled with interpretations, classifications, due to sophisticated thought, which have become incorporated into what seems to be fresh naïve empirical material' (Dewey, 1958, p. 37).

This quote, they argue, forestalls Koopman's criticism by anticipating the possible but erroneous conclusion that an experience 'seems to be fresh naïve empirical material', when in actuality it is already 'overlaid and saturated' with prior reflections and interpretations. Having made his position so clear, they argue, Dewey should not be presented with this charge on the basis of alleged moments of lack of clarity elsewhere. Second, Hildebrand and Pappas (2010) argue that Koopman's attack on experience as foundational, derived from Sellars and Rorty, is misdirected; their critique was of the conception of primary experience found in Cartesian philosophy-precisely the sort of dualist foundationalism that Dewey (and Berkeley before him) were trying to disprove in the first place:

'For the target of Sellars' critique is a certain conception of knowledge-experience in the modern sense; but this is not 'experience' in Dewey's dominant sense, namely, the best methodological starting point for a melioristic philosophy in a processual world' (Hildebrand and Pappas, 2010).

Dewey's 'experience', they maintain, is foundational only in that he argues that it is where we start from, and where we must return, in seeking resolution of our 
thinking and actions; neither of these ideas imply an unmediated essence on which our experiences draw.

The ultimate aim of Koopman's critique is to establish the value of his proposed 'third wave' pragmatism by both drawing on the strengths of, and highlighting the weaknesses of, classicopragmatism and neopragmatism. He argues that the linguistic turn of neopragmatism gave rise to a new technical vocabulary that would have enabled Dewey to clarify his antifoundationalist position:

'[Sellars and Rorty] fashioned a clever way of giving up the quest for the grounds of knowledge by favouring instead the project of specifying the field in which knowledge operates' (Koopman, 2009, p. 95).

Central to this argument is that our perceptions and experiences are recognised, understood and expressed through culturally distinctive linguistic concepts; thus uncovering the histories of their development and use is a sufficient description of coming to know and understand them, while avoiding any taint of foundationalism (ibid.). Based on their defences of Dewey summarised above, Hildebrand and Pappas attack this line of argument as 'a solution in search of a problem' (2010). They do nonetheless recognise the value of Koopman's attempt to recognise and seek to resolve long-standing tensions between pragmatists, and to set out in new directions by bringing in insights from a broader range of philosophers. In particular, Koopman intertwines different pragmatic traditions with a wider field of philosophers and sociologists, such as Foucault and Bourdieu, to present what he calls 'genealogical pragmatism' (2009, p. 10). This combines the power of Foucault's 'problematisation' of the present through a historical study of how ideas and objects came to be named, understood and used, with the power of Dewey's philosophy for reconstructing the present to work towards desired futures. In this spirit of pragmatist rapprochement, I will start to explore the value of this position below by thinking through how a pragmatic genealogical approach might both strengthen Dewey's central metaphor of growth, and add coherence to a pragmatist conception of curricular study. Alongside this, I want to suggest that this hybrid position still seeks, like Dewey, to circumscribe Berkeley's ontological 'quest' rather than refuting its possibility or necessity. To set up this part of my case, I want to turn first to another quotation from Dewey, not highlighted by Koopman, which could be interpreted as foundationalist in a different sense.

Dewey makes clear in Democracy and Education his strong commitment to science as a meliorative process of inquiry rather than as a fixed body of knowledge; however, there are passages in his later work that appear to contradict this:

'The scientific method is the only authentic means at our command for getting at the significance of our everyday experiences of the world in which we live' (Dewey, 1938, p. 111).

This implies that there is a unitary scientific method-a contention rejected by historians of science since Kuhn (Chalmers, 1982). Also, it claims for that method a monopoly on realising 'significance', thus inadvertently instrumentalising us as tools for the development of science rather than vice versa. However, like Koopman, I do not wish to press charges because there are mitigating circumstances. Dewey was writing immediately before World War II at a time of rising nationalism, bellicosity and irrationality in global politics; as is made abundantly clear elsewhere across his 
work, he saw scientific inquiry as the principle vehicle for human progress, and as an intrinsically moral practice aimed at increasing fulfilment at the expense of suffering - not as a fixed system discovered by scientists over the ages. A lapse into foundationalist language here may have been no more than a form of emotive emphasis, in the way I might exhort others to focus on 'the evidence' and 'the facts' in our current climate of 'post-truth' politics: my use of those terms would be metaphorical rather than ontologically foundational, an appeal to focus on what we can rationally assert and discuss rather than divide ourselves through prejudice. Yet I suggest that this lapse was indicative of something missing in Dewey's philosophy, the lack of which was exposed in this attempt to reach out to and convince others. My aim is thus to try to complete his anti-foundationalist jigsaw with an ontological piece. I will introduce this by examining his central metaphor of 'growth'. Dewey states:

'Since in reality there is nothing to which growth is relative save more growth, there is nothing to which education is subordinate save more education' (Dewey, 1966 [1916], p. 51).

Dewey describes growth as a melioristic process and as an end-in-itself: in persons, in education, and in a democratic society. To say that a person, or a society, grows through educational activity is in keeping with this metaphor; it suggests a process of becoming more fully human unimpeded by arbitrarily imposed or inherited limitations. Koopman's genealogical pragmatism might help to provide our metaphoric seedling with roots: a historical context that it can draw on in responding to the challenges of its present environment. From an educational perspective, this may be complementary to Dewey's active notion of responsive, relevant, intelligent enquiry that sits awkwardly with the idea of a formal curriculum since, by its nature, it lacks responsiveness to the aims, dispositions and needs of individual students:

'Too rarely is the individual teacher so free from the dictation of authoritative supervisor, textbook on methods, prescribed course of study, etc., that he can let his mind come to close quarters with the pupil's mind and the subject matter' (Dewey 1966 [1916], p. 109).

Dewey argued that it is the teacher's role to act as the bridge between students' interests and the accumulated fund of wisdom in a society. I suggest, however, that a genealogical conception of formal disciplinary study would support this role by encouraging teachers and students together to develop critical understandings of how each discipline came to be, how it works, its contemporary uses, its possible future developments, and its syntheses with other disciplines-rather than imbibing it as gospel with an emphasis on accurate reproduction. It would be about the intelligent engagement with, and use of, disciplinary traditions in relation to existing problems in the world, emphasising their social and historical context, their development over time, and their transformability in the present and future. The study of disciplines would thus become an empowering means to other ends-in-view rather than an end in itself, while still respecting their value and integrity as repositories of specialised social wisdom.

If we extend Dewey's metaphor of 'growth' further still, however, we can see its limitations. The 'indeterminacies' (Burke, 1994, p. 257) we experience-the challenges to our settled habits that spur our plants to growth-are like sunlight: when they appear, they stimulate and provide the energy for the growing process. But at the 
risk of overburdening this seedling metaphor, it appears to lack one essential element: the soil in which it is rooted. And while the parallel process of active inquiry and genealogical inquiry proposed by Koopman, entwining two competing pragmatist traditions, is conceptually satisfying and educationally productive, it still gives no sense of the source of those enculturated responses outside a linguistic analysis of their histories and possibilities on the one hand, and the immediacy of our experiences on the other. We should look to go further than 'specifying the field in which knowledge operates' (Koopman, 2009, p. 95), and responding intelligently to the stimulation we receive; we should try to understand why we receive such stimulation, and thus seek the sources of these indeterminacies. I suggest that Dewey's uncharacteristic foray into foundationalist language, which implied the prior existence of an underlying 'scientific method', was made due to a lack in his account of any such ontological soil; in seeking to communicate the urgent necessity of rational scientific thinking at a critical time he lacked something deeper and more resonant to link it to, an ethical imperative with inherent rather than instrumental value. In its absence, I suspect Dewey's exhortation to his Kappa Delta Pi society audience that they develop an 'intense emotional allegiance to the method' $(1938$, p. 100) left the majority, for whom that sort of affect is reserved for real people and humane ideals, feeling cold. Thus Berkeley also had a point in arguing there must be an ontological foundation to account for the very possibility of experience as well as to understand its operation. Rather than his all-seeing God, however, I propose 'dialogue across difference' as a generative ontological principle, and as an ethical imperative, for melioristic pragmatism-which I will explore in the next section.

\section{Dialogic Theory: Pragmatism's Ontological Soil?}

I have argued that pragmatism, a relatively new philosophical tradition developed in the late $19^{\text {th }}$ and early $20^{\text {th }}$ centuries, has roots in the early $18^{\text {th }}$ century. Similarly, dialogic theory was developed principally by the literary theorist Mikhail Bakhtin in the late 1910s and 1920s, thus making him a direct intellectual contemporary of Dewey. However, Bakhtin's work was only 'discovered' in the West in the late 1970s, and subsequently interpreted for education and instrumentalised as pedagogy there by, for example, Robin Alexander as 'dialogic teaching' and by Neil Mercer as 'exploratory talk'; this has since expanded rapidly in popularity as an educational approach (Howe and Abedin, 2013). More modestly, it has also been explored philosophically by Wegerif (2007), Kazepides (2010) and others. Like pragmatism, the roots of dialogic theory also extend back further-to Socrates, who wrote: 'Thinking is, precisely, the inward dialogue carried on by the mind itself without a spoken sound' (Plato, Sophist, 263e). This demonstrates an insight later clarified by Vygotsky as a basis of sociocultural theory: that thought and language are learned first through social interaction, and then internalised (Vygotsky, 1978, p. 57). Bakhtin developed this by arguing that dialogue consists of 'voices' - not just of people one talks to, but from books and other media, from history and folk culture across what he called 'Great Time' (Bakhtin, 2010, p. 170). Thus voices come from the outside in, they engage with other voices in our minds, and are transformed and re-voiced to others in a continuous chain of meaningful dialogue.

I will try to hybridise pragmatism and dialogic theory in three steps: First, I will argue that Wegerif's conception of 'dialogic space' offers a credible dialogic ontology that gives us a generative basis for human growth without evoking a metaphysical realm. Second, I will show how Bakhtin's concept of 'addressivity' further 
distinguishes dialogic from realist ontologies. Third, I will argue that the centrality of intersubjectivity to the concept of dialogic space affords an equally valuable ontological foundation for ethics as well.

Wegerif defines 'dialogic space' as that which 'opens up when two or more perspectives are held together in tension' (2007, p. 148); although we can never share another's perspective fully, the attempt to cross the gap invites new meanings to emerge from between positions. It is thus only inasmuch as we see something differently to others that we have any cause to discuss it, and doing so generates a dialogue around that shared object or idea. In building his case for a dialogic ontology around this metaphor, Wegerif draws on Derrida's playfully self-referential substitution of 'differànce' for 'différence'-differently spelt, but phonetically identical - to illustrate that the meaning of language is not inherent in the identity of words or concepts (ibid., p.22). The substitution of the 'à' into 'différence' changes the meaning of the word, but not through any fixed meaning of the letter itself; rather, it is the difference between the 'à' and the ' $\mathrm{e}$ ' in the context of the word that changes the meaning. It is only because the 'à' is in contrast, because it is 'not-e', that the new word has 'an almost infinite but indefinite meaning' (ibid., p. 23). The implication is that meanings neither have an ultimate origin, nor do they reach a conclusion; they occur within chains of dialogue without beginning or end, existing in the dialogic space that opens up between different perspectives. Drawing together the work of Heidegger, Merleau-Ponty and Bakhtin, Wegerif then advances his ontological argument: that we understand and appropriate the world through the adoption of new perspectives on it. Ultimately, this is to say that the world (as we know it) comes into being through the act of making meanings - in relation not to a physical or metaphysical reality but to 'original difference' (ibid., p. 26). It is immanent, unbounded and generative difference, always already there, as the progenitor of dialogic spaces and their emergent meanings. It is not a foundational reality because it is never fixed. It is best understood as provoking the linking of prior meanings into new meanings rather than inhering in them, as a process not an object. As such, I argue, it entirely complements both inquiry-based and genealogical pragmatism as a source for their quests for new understandings and responses; it also provides the ontological soil for Dewey's process of growth.

Another plank of a realist ontology is that 'truth' is a function of the accurate and justified representation of a statement to an underlying reality. Bakhtin's dialogic philosophy denied any such correlation, arguing instead that within a 'polyphony' it is possible for two or more contrasting voices to be true; the criterion of truth is thus not the representativeness of reality of any one statement, but the 'addressivity' of the shared dialogue to the enriching goal of engaging with and learning from difference (Robinson, 2011). Again, the parallels with Dewey's pragmatism are clear: inasmuch as it is valuable to talk about 'truth' at all, it is as the quality of an activity in which exploration of problems leads to personal and collective growth. However, Bakhtin's image of chains of dialogue made of interweaving strands, or voices, avoids having to make the outcome of the activity the sole test of its truthfulness, or in Dewey's terminology, its 'intelligence'. Instead, the process itself is afforded intrinsic value through being engaged in the humane response to difference. I say 'humane' to recognise that, for Bakhtin, a monologue is an interchange in which one seeks to dismiss or overrule the value of other voices, thus making for a violent process in which the productive exchange of meanings is impeded. Dewey also recognised the inherently educative value of genuine communication, and the ethical imperative of 
this in a democracy (1966 [1916], p. 5); this is relevant to my final step, which is to present a dialogic ontology as an ethical foundation.

In Bakhtin's work, and its development by Wegerif and others, we see dialogue both as a source of meaning and as a form of interrelation, in which we engage with and respond to others as if they really matter - whereby meaning itself emerges through the process of openly relating, with others at hand or at a distance, to shared ideas. This theme is developed by Biesta in his exploration of Levinas, who argues that we are not born thinking or knowing, but relating - and that the conscious 'self' is a construct that emerges slowly in childhood. The baby perceives no identity gap between self and mother until his or her perceptions accrue sufficient evidence that different perspectives on the world exist (2006, p. 52). So even our identity as perceivers is emergent; each of us is 'a-being-with-others' (ibid.) whose ontological status is founded in dialogue, or the response to difference. This argument also removes the cornerstone of Cartesian foundationalism by making self-awareness secondary to the experience of relating to others-so we cannot a priori ascribe an underlying reality either to the perceiver or the object perceived. Biesta takes this further by drawing on Arendt, who argues that our uniqueness makes interaction with other beings inherently unpredictable: we are not 'endlessly reproducible repetitions of the same model' (Arendt, 1977, p. 9). This means that our human encounters, when responsive to the unique person and situation rather than judgemental or instrumental, are also founded in difference. Biesta thus calls for education to focus on participants' 'coming into presence' (Biesta, 2001, p. 398) through intersubjective engagement.

Again, this resonates strongly with Dewey's position in Democracy and Education: 'Not only is social life identical with communication, but all communication ... is educative' (1966 [1916], p. 5). Furthermore, his theory of communication is fully compatible with the concept of dialogic space. He argues that one must reformulate one's ideas in accordance with one's judgement of another's understanding: 'seeing it as another would see it ... [so] that he can appreciate its meaning' (ibid., pp. 5-6). New meanings and understandings, then, emerge from the attempt to communicate with others; this process is inherently relational, ethical and educative. And again, a dialogic ontology particularly complements genealogical pragmatism, which emphasises the uniqueness of the situations in which we experience differences because of their temporal and cultural contingency.

Bringing these three strands together, I argue that a dialogic ontology is fully compatible with pragmatism: it offers a valuable non-metaphysical foundation for pragmatism that provides an ever-generative source of meanings and problems, while protecting it from lapses into involuntary realism and supporting its central metaphor of growth. It broadens pragmatism's criteria for value or truth to encompass authentic engagement with difference in itself, as well as the results of any such engagement. Finally, it roots the ethical nature of our interactions in something deeper than our accidental cultural history of meaning-making and rules: our fundamentally dialogic identities.

\section{CONCLUSION: SOME NEW METAPHORS FOR A DIALOGIC PRAGMATISM}

I have argued both for Berkeley's essential pragmatism, and for his prescience in believing there to be a need for an ontological foundation for it. His foundation was 'esse est percepi'. Yet having debunked the foundational realism of both the perceiver and the perceived, how else might this be formulated? My suggestion is 'esse est 
respondere et respondi': 'to be is to respond, and be responded to'. The concept of response to difference as an ontological principle focuses on the interrelation between perceiver and perceived, and thus makes no metaphysical demands. That which exists does so only as a transitory process: a limitless chain of dialogue, the call and response of difference. Once again, this idea is hinted at near the start of Democracy and Education, when Dewey asks how ideas, unlike objects, can be transmitted:

'... by means of the action of the environment in calling out certain responses. ... The things with which a man varies are his genuine environment. ... In brief, the environment consists of those conditions that promote or hinder, stimulate or inhibit, the characteristic activities of a living being' (p. 11, italics in original).

Dewey here argues that we are defined by how we change- by what we respond to and how-and by our distinctive chains of interaction with the environments (including other people) which we shape and are shaped by in turn. It is only a small step from here to an ontology of difference that breathes generative life into this process.

Finally, I offer the metaphor of 'realisation', or 'realising', to encapsulate both the process and experience of meaning-making as understood through a dialogic ontology. Its everyday double meaning of both making a connection in thought, and of bringing something into being, is useful to us here. Firstly, to say that both meaningful thoughts and actions are 'realised' through responding to difference helps to strengthen Dewey's argument against mind/world dualism by suggesting no material difference between them. Secondly, the metaphor of 'realisation' seeks to capture something of our experience of agency when we respond powerfully to new ideas and situations - the sense that they allow new possibilities to come into being that may change us and our environment. Finally, 'realisation' seeks to capture the ever-emergent, generative nature of our encounter with difference, in contrast to the idea of a fixed underlying reality: an immanent, humane and creative principle to which I hope Dewey's student audience, and perhaps the man himself, might have authentically pledged allegiance. ${ }^{1}$

Correspondence: Dr Rupert Higham, London Centre for Learning and Leadership, UCL Institute of Education, Ldondon, UK.

Email: rupert.higham@ucl.ac.uk

\section{NOTE}

1. I am greatly indebted to David Hildebrand for his generous comments on a prior version.

\section{REFERENCES}

Bakhtin, M. M. (2010) Speech Genres and Other Late Essays (Texas: University of Texas Press). Berkeley, G. (1988 [1710]) A Treatise Concerning the Principles of Human Knowledge (London, Penguin Classics). 


\section{R. Higham}

Berkeley, G. (1948) An Essay Towards a New Theory of Vision, in: A. Luce and T. Jessop (eds.), The Works of George Berkeley, Bishop of Cloyne (Vol. 1) (Edinburgh, Thomas Nelson and Sons).

Biesta, G. (2006) Beyond Learning: Democratic Education for a Human Future (Boulder, CO, Paradigm Publishers).

Biesta, G. J. (2001) How Difficult Should Education Be? Educational Theory, 51.4, pp. 385-400.

Chalmers, A. (1982) What is This Thing Called Science? (Milton Keynes, OUP).

Dewey, J. (1938) Experience and Education (New York, Macmillan).

Dewey, J. (1958) Experience and Nature (Mineola, NY, 1958).

Dewey, J. (1966 [1916]) Democracy and Education (New York, The Free Press).

Frega, R. (2009) Review of Pragmatism and Transition: Historicity and Hope in James, Dewey and Rorty, European Journal of Pragmatism and American Philosophy, 1.1, pp. 1-7. Available online at: http://nx.journalofpragmatism.eu/wp-content/uploads/2009/11/11-koopman.pdf (accessed 20 November 2016).

Friedman, L. (2003) Pragmatism: the Unformulated Method of Bishop Berkeley, Journal of the History of Philosophy, 41.1, pp. 81-96.

Hildebrand, D. L. and Pappas, G. (2010) Review of Colin Koopman, Pragmatism as Transition: Historicity and Hope, in James, Dewey, and Rorty, Notre Dame Philosophical Reviews. Available online at: http://ndpr.nd.edu/news/24466-pragmatism-as-transition-historicity-andhope-in-james-dewey-and-rorty/ (accessed 20 November 2016).

Howe, C. and Abedin, M. (2013) Classroom Dialogue: A Systematic Review Across Four Decades Of Research, Cambridge Journal of Education, 43.3, pp. 325-356.

Kazepides, T. (2010) Education as Dialogue (Montreal, Quebec, McGill-Queen's University Press).

Koopman, C. (2009) Pragmatism as Transition: Historicity and Hope in James, Dewey, and Rorty (New York, Columbia University Press).

Margolis, J. (2012) Review of Pragmatism as Transition; Historicity and Hope in James, Dewey and Rorty, by Colin Koopman. Transactions of the Charles S. Peirce Society, 48.2, pp. 228-234.

Patey, D. L. (1986) Johnson's Refutation of Berkeley: Kicking the Stone Again, Journal of the History of Ideas, 47.1, pp. 139-145. Available online at: https://doi.org/10.2307/2709600 (accessed 20 November 2016).

Robinson, A. (2011) Bakhtin: Dialogism, Polyphony and Heteroglossia, Ceasefire, XXXXX. Available online at: https://ceasefiremagazine.co.uk/in-theory-bakhtin-1/ (accessed 10 April 2018).

Sellars, W. (1956) Empiricism and the Philosophy of Mind, Minnesota Studies in the Philosophy of Science, 1.19 , pp. 253-329.

Wegerif, R. (2007) Dialogic Education and Technology (New York: Springer).

Wegerif, R. (2008) Dialogic or dDialectic? The Significance of Ontological Assumptions in Research on Educational Dialogue, British Educational Research Journal, 34.3, pp. 347-361. 